\title{
What kind of social justice does social work seek?
}

\section{John Solas}

\section{Why social justice matters}

Before considering conceptions of social justice, it is important to understand why it matters, since this is a matter of opinion rather than fact (Donnison, 1991). There is perhaps little, if any, doubt about the significance of this question among people in poor countries. They have become accustomed to facing the prospect of destitution, violence and death. Even in an affluent country like Australia, in the middle of one of the country's wealthiest capital cities (Sydney) and only a short distance from the intellectual hub of one of its most prestigious sandstone universities, lies Redfern, where the average life expectancy of its Indigenous residents is not much longer than those in remote homeland communities. The average life expectancy of an Aboriginal boy in Wadeye, a typical Aboriginal community in the northwest of Australia's Northern Territory, is less than 50 years (Graham, 2006). While people might agree that this is pitiable, not all are apt to conclude that the situation mirrors the way a society is organized and governed or that its public institutions are not all that they should be. People might concede that poverty is bad, but not consider inequality unjust. As a corollary, they also differ over what, if anything, is owed to the poor. However, no one can deny that the gap between rich and poor not only persists, but is becoming progressively wider. Social justice matters, then, because of increasing immiseration. It is bound to matter even more when the intolerable hardship it causes can no longer be politically legitimitized and attenuated.

A theory of social justice is needed, therefore, for both humanitarian and pragmatic (largely security) reasons. However, not just any theory will do. There are, needless to say, misguided and ill-conceived theories which do more harm than good. According to one such theory, justice demanded that Aboriginal children be taken and raised by white people. All Australians are compelled to live with the legacy of that disastrous doctrine, and no less for the lack of a government apology as the theory itself.

What kind of theory of social justice do we need, then? It is necessary to have a theory of social justice that does more than respond to inequality as though it were bad but inevitable. Rather, such a theory must offer a stronger response to inequality, one that recognizes it as a gross and unwarranted injustice. The question is, however, is this the type of theory that informs social work? There is, as will be argued, a question mark about this. But, again, before I argue the point, it is important to consider the range of theories of justice on offer.

\section{Theories of justice}

Justice understood not simply as a virtue of individuals but of societies is dominated by a narrow range of theories (Rawls, 1971). They range from traditions that stress the concept of desert or merit, through those based on rights, to others for which the notion of a social contract is central (MacIntyre, 1988). However, conceptions of justice which have become prominent in recent times have tended to be teleological and based on some variant of the utility principle (Scanlon, 1988), according to whom 'utilitarianism occupies a central place in the moral philosophy of our time' (p. 103). It is a view which few people would claim to, or perhaps know they hold. But it is, nonetheless, 'one to which they find themselves pressed when they try to give a theoretical account of their moral beliefs' (Scanlon, 1995). Indeed, as Reamer (2006) observes, not only has utilitarianism historically been the most popular teleological ethical theory, it 'has, at least implicitly, served as justification for many 
decisions made by social workers' (p. 66). According to Williams (2006), 'Utilitarianism is the most ambitious of extant ethical theories. It aims to yield the most definite results and is willing to press them

most firmly against everyday ethical beliefs' (p. 92).

There are many species of utilitarianism. These theories disagree about how utilities are to be assessed and about other questions: whether, for instance, it is the individual act that should by justified in terms of maximizing utility, or instead some rule, practice or institution. This is the difference between direct and indirect utilitarianism (Williams, 2006). All the variants agree on aggregating utility, that is to say, adding

together in some way the utility of all individuals involved (Sen and Williams, 1982).

An essential characteristic of utilitarian theories of justice is that good is defined independently from right, so that whatever is judged good for people is good whether right or not. The main idea inherent in utilitarianism, especially according to the classical liberal, or more precisely, libertarian doctrine (expounded by Friedman, 1973, Hayek, 1976 and von Mises, 1953), is that society is just, when its major institutions are arranged so as to achieve the greatest net balance of satisfaction summed over all the individuals belonging to it. The problem, however, is that it does not matter, except indirectly, how the sum of satisfactions (i.e. the greatest good or happiness) is distributed among individuals over time. The aim is simply to maximize the allocation of the means of satisfaction, that is, rights and duties, opportunities and privileges, and various

forms of wealth. However, when the principle of utility is satisfied there is no assurance that everyone benefits. In fact, the principle requires that some individuals should accept lower prospects of life for the gratification of others (Barry, 1989, 1995). Utilitarian theories of justice promise only equity, not equality, and even equity is not guaranteed, since felicific calculations of good or happiness have proved to be illusive. The point is, however, that in a finite world, everything that anyone has is something that others cannot have. Deprivation cannot be sanctioned by the claim that it is for the greater good.

To discriminate between individuals on the basis of utility, furthermore, is to treat them as means to ends. This has often been done for the greater good, but is it just? For anyone who thinks it imperative that a person ought never to be treated as a means to someone else's ends, the answer is a categorical no (Kant, 1797). Those who believe the ends justify the means may still be concerned about poverty in the middle of plenty. Utilitarians readily concede that everyone is to count as one. But no one counts as more than one. It is, therefore, left to charity, patronage or serendipity to intervene beyond the point of fiduciary responsibility. Benevolent behaviour goes far beyond the utilitarian sphere of justice. Finally, as, Nussbaum (2006) contends, 'utilitarianism's commitment to aggregation creates problems for thinking well about marginalized or deprived people, for whom some of the opportunities that Utilitarianism puts at risk may have an especially urgent importance' (p. 73). The assimilation does not give their convictions any particular weight. It requires an individual to abandon any stand of principle or deeply held conviction if a large enough aggregate of preferences, of whatever kind, favours the contrary. The segregation between good and right makes it possible for aggregated acts, rules or preferences to arise which a minority of the population considers offensive, or worse (e.g. the ever popular preference for maximizing the utility of racial purity and superiority). It would seem, then, that those who possess a strong sense of justice will find theories of justice based on utilitarianism wanting. At best, they provide a starting point for a theory of social justice. Yet utilitarianism is, in fact, precisely the kind of justice which professional associations of social work have tended to call social justice. 


\section{The social justice of the International Federation of Social Workers}

An account of social justice is presented in the International Federation of Social Workers' (IFSW) Code of Ethics (1999) (which incidentally, has also been adopted by the International Association of Schools of Social Work, 2004). The current version of the Code states that 'social workers have a responsibility to promote social justice, in relation to society generally, and in relation to the people with whom they work' (2005: 2). This means:

1. Challenging negative discrimination. (In some countries the term 'discrimination' would be used instead of 'negative discrimination'. The word 'negative' is used here because in some countries the term 'positive discrimination' is also used. Positive discrimination is also known as 'affirmative action'. Positive discrimination or affirmative action means positive steps taken to redress the effects of historical discrimination against the groups named above). Social workers have a responsibility to challenge negative discrimination on the basis of characteristics such as ability, age, culture, gender or sex, marital status, socio-economic status, political opinions, skin colour, racial or other physical characteristics, sexual orientation, or spiritual beliefs.

2. Recognizing diversity. Social workers should recognize and respect the ethnic and cultural diversity of the societies in which they practise, taking account of individual, family, group and community differences.

3. Distributing resources equitably. Social workers should ensure that resources at their disposal are distributed fairly, according to need.

4. Challenging unjust policies and practices. Social workers have a duty to bring to the attention of their employers, policy-makers, politicians and the general public situations where resources are inadequate or where distribution of resources, policies and practices are oppressive, unfair or harmful.

5. Working in solidarity. Social workers have an obligation to challenge social conditions that contribute to social exclusion, stigmatization or subjugation, and to work towards an inclusive society.

An earlier version of the IFSW Code of Ethics was even less explicit about what social justice entailed. In the 1994 draft, it was listed as the fourth of 12 basic principles and it was simply noted that 'social workers have a commitment to principles of social justice' (p. 2).

Despite the brevity of the IFSW's description of social justice, it is enough to gain an indication of the kind of theory it espouses. What is remarkable, and most telling, is the IFSW's stark omission of any

direct reference to the attainment of equality. Rather, it is equity that is sought in matters of resource allocation. Equity does not guarantee an even distribution of resources and this is certainly in keeping with the basic principles of utilitarian justice. In addition, the task of distribution is limited to resources that are at workers' disposal. Injustice, according to this distributive norm, would be largely defined in terms of monopolies (Mullaly, 2002). Market failures are no less a concern to utilitarianism, focused as it is on the satisfaction of want rather than need. There is no suggestion, either, that anything more need be done to alter distributional schemes that yield an unjust share of resources other than publicizing it, i.e. 'bringing it to the attention of employers, policy-makers, politician and the general public'. 
Moreover, while maldistributions need to be addressed, a more fundamental concern is the institutional context which gives rise to them. 'Whether a distribution is just depends upon how it came about' (Norzick, 1974: 153). Inequality is not simply or primarily the result of unequal distributions of wealth and income. An unjust distribution, as Walzer (1983) observes, stems from unjust social structures, processes and practices. Concern about the endproduct of distributional patterns is important, but it offers no more justice than utilitarianism provides if the basic allocation structures responsible for producing and maintaining unequal shares of the social product go unchallenged.

Anti-discrimination forms an integral part of the IFSW's conception of social justice. 'Social workers have a responsibility to challenge negative discrimination' and, by extension, encourage 'affirmative action' and 'positive discrimination'. This is certainly in keeping with the basic principle of utility that every one is to count for one and only one. One's own good, happiness, pleasure or welfare, etc., is as important as any one else's. However, this does not prevent one from being treated indiscriminately for maximum benefit. The point at issue is that people ought to be treated with respect for their personhood. The happiness they receive is beside the point. And, as Shapiro (1995) argues, 'much of the trench warfare around affirmative action has little impact on the structure of income distribution' (p. 122). Young (1990: 199) adds:

\section{even if strong affirmative action programs existed in most institutions, however, they would have only a minor effect in altering the basic structure of group privilege and oppression ... Since these programs require that racially or sexually preferred candidates be qualified, and indeed often highly qualified, they do nothing directly to increase opportunities for Blacks ... or women whose social environment and lack of resources make getting qualified nearly impossible for them.}

While affirmative action has made some progress in redistributing positions among formerly excluded groups, at least by mainstream standards, there has been significantly less success in instituting more radical proposals for making the definition of and admission to these positions equally just. That is to say, whereas certain individuals have benefited from positive discrimination, the relative position of the devalued groups they stem from continues to be marginal. Little wonder that positive discrimination receives a good deal of support from those whose affluence makes preferential treatment unnecessary (Young, 1990). Raising the expectations of those discriminated against does, however, have the effect of adding to the competitive strains between lower- and middle-class aspirations. This is apt to 'feed racism and destroy what otherwise might be natural political alliances in a campaign for redistributive change' (Shapiro, 1995).

There is also no mention of rights and opportunities which would have made it clear that a conception of social justice was being advanced which exceeded the bounds of utilitarian concerns. For utilitarianism harbours a strong antipathy towards rights, especially natural and moral rights. It takes little account of their fulfilment or violation (Norzick, 1974). According to the founder of utilitarianism, Jeremy Bentham (1789), any talk of rights outside a purely legal context was just nonsense. And, what are rights without (fair as opposed to formal) opportunities to exercise them? Resources by themselves are inadequate as an index of wellbeing, because individuals have varying needs for them. There is no doubt about the importance of economic equality; but for what? Overcoming economic injustice is not an end itself. There is a multiplicity of values which cannot be reduced to general utility. Social justice requires the fair and equal access to rights and opportunities as well as resources. Consistent with utilitarian theories of justice, the Code of Ethics consists of a plurality of principles without any explicit method, or priority rules, for weighing these principles against 
one another (For example, how is account to be taken of 'individual, family, group and community differences'? Which takes priority? When? Why, or why not?). Rather, in the absence of a firmer felicific calculus, workers are simply to strike a balance by intuition, or by what seems to them to be right. A theory of social justice that places heavy reliance on balancing acts lacks stability, consistency and direction. There will always be trade-offs, as no two cases are ever exactly alike. What separates them must be a matter of principle, in the sense of a summary and discursively statable description that does not have to rely on vague references to degree, that is, a balance between too much and too little. In addition, relying on intuition makes criticism impossible since this makes personal moral reactions self-justifying; if moral distinctions are just what a worker's moral sense intuits and nothing else, then there is no room for argument about whether he or she might be wrong. What is more, social justice is not ranked the first of the five cardinal values comprising the IFSW's Code of Ethics. Rather, it is regarded as a subsidiary value.

\section{Radical egalitarianism}

Many regard even a small advance on utilitarian justice as utopian (Norzick, 1974). Of course, there was a time when utilitarianism itself was thought to be nothing short of a radical ideal (Ryan, 2004). However, who now sees the justice in it? From the point of view of a vast and ever growing proportion of the world's population, the establishment of a more comprehensive and generous system of social justice is not an abstract matter, but rather a matter of life or death. If social work is genuinely concerned about the welfare of these people, then it must reject minimalist schemes of social justice like utilitarianism and, by extension, libertarianism. Enlarging the scope of social justice will be expensive. It will incur a cost to individual liberty that minimalists would deem unjustifiable. However, how long can we continue to limit the pursuit of social justice in the face of rising injustice? Can we not afford social justice? With the prospect of greater equality, it becomes possible to have more cooperative, inclusive and peaceful societies, which even the cost-counters and bottom-liners are liable to find more efficient and profitable.

Despite the fact that theorists disagree about the precise formulation of the first principles of social justice, they have, as MacIntyre (1988) has argued, 'by and large agreed on what such principles should be designed to achieve' (p. 344). On this point, MacIntyre (1988: 344) is worth quoting at length:

Just because the principles of justice are to govern the tallying and weighing of preferences, they must provide, so far as is possible, a justification to each individual qua individual for the tallying and weighing [of] (sic) his or her particular preferences in the way that they do. So any inequality in the treatment of individuals qua individuals requires justification. Justice is prima facie egalitarian. The goods about which it is egalitarian in this way are those which, it is presumed, everyone values: freedom to express and to implement preferences and a share in the means required to make that implementation effective. It is in these two respects that prima facie equality is required.

Of course, it is precisely at this point that the argument between theorists begins, and regrettably, ceases to be productive. Nevertheless, this does not mean that it is impossible to get beyond the impasse. The first and most important step is to pursue equality as a inviolable political principle, i.e., that people must be treated as equals, rather than merely defend the more illusive and contentious notion that people are equal in some intrinsic way(s) (Williams, 2006). As Williams (2006) observed, merely asserting that people are equal by virtue of 
being human is a necessary but insufficient reason to guarantee equality between them. As the basis for equality, natural entitlement is weak and insecure. It does little more than serve as a reminder that human beings are human beings, and hence, share a common humanity (Cupit, 2000). Political conviction is required to value and pursue the claim that equality be accorded to every individual, and it must do so not because of some innate or universal characteristic, but precisely because of the significant inequalities that exist between individuals. It is a conviction which social work will have to act upon if it intends to seek a more radically egalitarian form of social justice, since to doubt the claim that we must be regarded as fundamentally equal is to cast no less doubt upon the principle that justice requires people to be treated as equals. And, if the requirement to treat individuals as equal is to prevail for the sake of justice, then merely abstaining from engaging in unequal treatment will not be enough. In short, while not interfering in people's lives may avoid being directly implicated in negative discrimination, it nevertheless falls short of treating them as equals. To exemplify the point, by not taking an active part in genocide or a pogrom one may claim to avoid being party to unequal treatment: however, it does nothing to promote equality. What is central is the sovereignty, and hence, incomparability, of the individual. Does this imply that a Hitler, Stalin or Pol Pot is equal to a Gandhi, Dalai Lama or Mandela? The short answer is yes. The commitment to radical egalitarianism would hardly be genuine were exceptions made. And, if the commitment were indeed true, then there is no comparison. One is not superior to another, and none has a natural right to command any other. It also possible to add to this resolution social work's own long and cherished tradition of valuing the individual. But none of this justifies non-interference in the face of unequal treatment. On the contrary, intervention is justified any time the sovereignty of an individual, as a separate and independent being, is jeopardized.

For the Code of Ethics to convey a radically egalitarian conception of social justice, the IFSW would need to consider, as a minimum, making a commitment to equality, in every sense of the word, rather than equity, fundamental. No dimension of equality - cultural, economic, political or social - is more fundamental than the others. Anything less would ultimately be liable to justify the replacement of one form of inequality with another. Radical egalitarianism insists on equality with respect to the distribution of each and every good with which social justice is concerned. Many attempts have been made to devise a suitable, common metric. John Rawls' (1971) equalizer is foremost among them (Freeman, 2007). Rawls (1971) maintains that a leximin criterion of equality is just enough. This criterion is certainly an advance on any utilitarian calculus. Yet, while the leximin aims to improve the conditions of the worst off, it nevertheless permits inequalities to persist between them and the better-off. But of course Rawls never intended to develop an equalisandum or equal measure (Jencks, 2002), who considered 'justice as fairness'. The question remains, why tolerate inequality

of any kind or degree? Why not agree to start from, and maintain, a baseline of strict equality? Moreover, enabling people to have an equal start in life does not obviate the need for further concern. Radical egalitarians recognize that the primary subjects of justice are the institutional arrangements that shape people's life chances over time. Injustice resides in the social order, not in people (Hattersley, 2006). It is the (dis)order of things that is responsible for turning the natural diversity of human beings into oppressive hierarchies. One passage out of this problem, then, is to call on the ingenuity of the oppressed to describe, if not quantify, their suffering. Anything less places the quest for full social justice in question. 


\section{References}

Barry, B. (1989) Theories for Justice. University of California Press.

Barry, B. (1995) Justice as Impartiality. Oxford: Clarendon Press.

Bentham, J. (1789) An Introduction to the Principles of Morals and Legislation. New

York: Hafner.

Cupit, G. (2000) 'The Basis of Equality’, Philosophy 75: 105-25.

Derrida, J. (1976) Of Grammatology. Johns Hopkins University Press.

Donnison, D. (1991) A Radical Agenda: After the New Right and the Old Left. London:

Rivers Oram Press.

Friedman, M. (1973) The Machinery of Freedom. Chicago, IL: University of Chicago

Press.

Graham, C. (2006) ‘Billion Dollar Question - Indigenous Disadvantage’, Impact

(Autumn): 5-7.

Hattersley, R. (2006) 'Is Equality Outdated?', The Political Quarterly 77: 3-11.

Hayek, F. (1976) The Mirage of Social Justice: Law, Legislation and Liberty, vol. 2.

London: Routledge and Kegan Paul.

International Association of Schools of Social Work (IASSW) (2004) 'Ethics in Social

Work; Statement of Principles’. Available online at: http://www.iassw-aiets.org/

(accessed January 2008).

International Federation of Social Workers (IFSW) (1999) Code of Ethics. Canberra:

AASW.

Kant, I. (1797) Metaphysical Elements of Justice, ed. and trans. John Ladd. Indianapolis:

Hackett.

MacIntyre, A. (1988) Whose Justice? Which Rationality? University of Notre Dame

Press.

Mullaly, B. (2002) Challenging Oppression: A Critical Social Work Approach. Oxford:

Oxford University Press.

Norzick, R. (1974) Anarchy, State and Utopia. New York: Basic Books.

Nussbaum, M. (2006) Frontiers of Justice. Cambridge, MA: Harvard University Press.

Rawls, J. (1971) A Theory of Justice. Cambridge, MA: Harvard University Press.

Reamer, F. (2006) Social Work Values and Ethics. New York: Columbia University

Press.

Ryan, A., ed. (2004) John Stuart Mill and Jeremy Bentham: Utilitarianism and Other Essays. London: Penguin.

Scanlon, T. (1988) 'Contractualism and Utilitarianism', in A. Sen and B. Williams (eds)

Utilitarianism and Beyond, pp. 103-28. Cambridge: Cambridge University Press.

Sen, A. and B. Williams, eds (1982) Utilitarianism and Beyond. Cambridge: Cambridge University Press.

Shapiro, I. (1995) 'Why the Poor Don’t Soak the Rich', Daedalus (Winter): 118-28.

Von Mises, L. (1953) The Theory of Money and Credit. New Haven, CT: Yale University Press.

Walzer, M. (1983) Spheres of Justice. New York: Basic Books.

Williams, B. (2005) In the Beginning was the Deed. Princeton, NJ: Princeton University

Press.

Young, I. (1990) Justice and the Politics of Difference. Princeton, NJ: Princeton University Press. 